\title{
Effect of thyroidectomy upon seasonality in rams
}

\author{
T. J. Parkinson ${ }^{1}$ and B. K. Follett ${ }^{2}$ \\ ${ }^{1}$ Department of Veterinary Surgery, University of Bristol, Langford House, Langford, Bristol BS18 7DU, \\ $U K$; and ${ }^{2}$ AFRC Group on Photoperiodism and Reproduction, School of Biological Sciences, University of \\ Bristol, Bristol BS8 1UG, UK
}

\begin{abstract}
Experiments were conducted to examine whether seasonal breeding patterns of male sheep are abrogated by thyroidectomy. In Expt 1, Welsh Mountain rams were thyroidectomized in early autumn (September) and then maintained on either $16 \mathrm{~h}$ light: $8 \mathrm{~h}$ dark (long days; $n=6$ ) or $8 \mathrm{~h}$ light:16 h dark (short days; $n=6$ ) for 8 months. Intact rams ( $n=6$ per group) were also housed in long or short days, or in natural photoperiods. Results were similar in animals housed on long or short days. In thyroidectomized rams, plasma FSH concentrations and scrotal circumference were maintained at values typical of the breeding season throughout the investigation, whereas in intact animals both reached a nadir in December and January. In Expt 2, a further 11 rams were thyroidectomized in March and, together with 23 intact animals, were maintained thereafter in natural photoperiods. In control rams, scrotal circumference increased slowly between May and September, whereas in thyroidectomized animals the circumference increased rapidly in the first 4 weeks following thyroidectomy $(3.7 \pm 0.7 \mathrm{~cm})$, with a further increase $(5.9 \pm 1.0 \mathrm{~cm})$ in the next 4 weeks. The scrotal circumference of thyroidectomized rams was therefore significantly $(P<0.01)$ greater than that in intact animals between April and August. Plasma FSH concentrations were significantly $(P<0.01)$ higher in thyroidectomized than in control rams by two weeks after surgery. These results indicate that thyroidectomy overcomes the seasonal (or photorefractory) inhibition of reproductive activity in rams and supports a key role for thyroid hormones in the expression of seasonal patterns of breeding activity.
\end{abstract}

\section{Introduction}

Seasonal patterns of reproductive activity are exhibited by many animals, across a considerable phylogenetic spectrum. In temperate latitudes, photoperiodic changes are a key element in this seasonality, acting in some species by driving the secretion of gonadotrophins fairly directly and sometimes by phasing an internal endogenous rhythm, so leading to alternating periods of reproductive activity and quiescence (for reviews see Nicholls et al., 1988a, b). In mammals, the physiological transmission of photoperiodic information is effected by initial transduction of daylength into a neural signal within the suprachiasmatic nucleus, which then changes the duration of nocturnal secretion of melatonin by the pineal gland (see Karsch et al., 1984). These daily patterns of melatonin secretion are decoded somewhere within the brain or pituitary and, through unknown pathways, affect the transitions between breeding and non-breeding seasons by altering circulating gonadotrophin concentrations (Barrell and Lapwood, 1979; Legan and Karsch, 1980; Lincoln and Short, 1980). It is therefore possible to alter the timing of the breeding season by providing artificially controlled daylength (Yeates, 1949; Lincoln and Short, 1980; Poulton and Robinson, 1987), or strategic administrations of melatonin (Lincoln and Ebling,

Received 5 July 1993.
1985; English et al., 1986; Poulton et al., 1987; Ward and Williams, 1987). However, it is important to realise that such photoperiod- or melatonin-based manipulations of the breeding season only advance or retard the next period of reproductive activity and do not extend the period indefinitely $\left(\mathrm{O}^{\prime}\right.$ Callaghan et al., 1991; Robinson et al., 1992). Refractoriness invariably develops and the breeding season ends spontaneously.

The neural mechanisms underlying the development of refractoriness (or the expression of the endogenous reproductive rhythm) are still unknown. However, a significant breakthrough came when it was discovered that thyroid hormones seem necessary for refractoriness to be expressed. In seasonally breeding male birds (for example starling and quail) maintained under stimulatory photoperiods, thyroidectomy prevents the expression of photorefractoriness and also causes its spontaneous dissipation once it has developed (Wieselthier and van Tienhoven, 1972; Goldsmith and Nicholls, 1984; Dawson et al., 1985; Follett and Nicholls, 1985). Conversely, thyroid hormone replacement reinstates photorefractoriness (Goldsmith et al., 1985). This unexpected observation seems of generic importance, since in Welsh Mountain and Suffolk ewes that were either thyroidectomized (Nicholls et al., 1988b; Moenter et al., 1991; Webster et al., 1991a, b) or rendered hypothyroid by methylthiouracil administration (Follett and Potts, 1990) development of seasonal anoestrus was prevented or attenuated. Equally, thyroid hormone replacement leads to the normal Downloaded from Bioscientifica.com at 04/26/2023 11:19:06AM 
Table 1. Details of radioimmunoassay reagents and validation criteria

\begin{tabular}{|c|c|c|c|c|c|c|c|}
\hline Assay & Sample & Standard & Label & Antiserum & $\begin{array}{l}\text { Sensitivity } \\
\left(\mathrm{ng} \mathrm{ml}^{-1}\right)\end{array}$ & $\begin{array}{c}\text { Intra-assay } \\
\text { CV (\%) }\end{array}$ & $\begin{array}{c}\text { Interassay } \\
\text { CV (\%) }\end{array}$ \\
\hline FSH & $50 \mu \mathrm{I}$ & LER 1976-A2 & {$\left[{ }^{125}\right.$ I]LER $1976-\mathrm{A} 2$} & NIDDK anti-oFSH & 0.05 & 11.8 & 14.2 \\
\hline TSH & $50 \mu \mathrm{l}$ & NIDDK bTSH-I & {$\left[{ }^{125}\right.$ I]NIDDK bTSH-1 } & NIDDK anti-oTSH & 0.05 & 10.9 & 13.4 \\
\hline Prolactin & $4 \mu \mathrm{l}$ & NIDDK oPRL-12 & {$\left[{ }^{125}\right.$ I]NIDDK oPRL-12 } & McNeilly $2070^{\mathrm{a}}$ & 0.02 & 6.0 & 15.0 \\
\hline Thyroxine & $5 \mu \mathrm{l}$ & Thyroxine $^{\mathrm{b}}$ & ${ }^{125}$ I]Thyroxine ${ }^{c}$ & Biogenesis Ltd ${ }^{d}$ & 0.2 & 5.7 & 9.5 \\
\hline
\end{tabular}

${ }^{a}$ Antiserum to oPRL was donated by A. S. McNeilly (MRC Centre for Reproductive Biology, Edinburgh, UK); 'bigma Chemical Co, Poole, UK; ${ }^{c}$ Amersham International plc, Amersham; ${ }^{\mathrm{d} B i o g e n e s i s ~ L t d, ~ B o u r n e m o u t h . ~}$

expression of the breeding season (Webster et al., 1991b). There is much less information for male mammals: Jaquet et al. (1986) reported that testicular regression was slower in thyroidectomized than in intact male mink, while in rams the acute effects of thyroidectomy upon seminal characteristics were reported by Brookes et al. (1965) and Chandrasekhar et al. (1985) to be slight during the first 8 weeks of treatment, although results of studies of gonadotrophin secretion were less clear (Chandrasekhar et al., 1985). Finally, in red deer (Cervus elaphus) thyroidectomy nearly abolished the nonbreeding season, and animals retained full-grown testes throughout the year (Shi and Barrell, 1992).

The present study was undertaken to examine the effect of thyroidectomy upon testicular function in Welsh Mountain rams, maintained in either controlled or natural photoperiods. Our intention was to determine whether the non-breeding season would also be abolished in this species. The key parameters measured were scrotal size and FSH secretion patterns. A preliminary account of these investigations was presented to the Society for the Study of Fertility in July 1992.

\section{Materials and Methods}

\section{Experiment 1(a)}

This experiment examined the effect of removing the thyroids from rams that were at the peak of their annual testicular cycle. Starting in early August, thirty-two Welsh Mountain rams were housed under natural photoperiod for 4 weeks, 14 were then thyroidectomized under general anaesthesia (halothane- $\mathrm{O}_{2}$ induction and maintenance). A further 12 rams were sham operated, also under general anaesthesia. In mid-September, seven thyroidectomized and six sham-operated rams were placed in an artificial photoperiod of $16 \mathrm{~h}$ light: $8 \mathrm{~h}$ dark (long days), and seven thyroidectomized plus six shamoperated animals in $8 \mathrm{~h}$ light:16 h dark (short days). A further group of intact animals $(n=6)$ were maintained under natural photoperiod. The animals remained under these photoperiodic regimens for the entire experiment (September 1991-April 1992). The rams housed in controlled photoperiods were in light-proof, forced-ventilation sheds, where they were kept in groups, bedded on straw. All rams had access to hay and water ad libitum with about $250 \mathrm{~g}$ sugar beet pulp every day.

Two weeks after surgery, and once per month thereafter for a further 6 months, a jugular venous cannula was placed in each ram and blood samples $(3 \mathrm{ml})$ were collected every $2 \mathrm{~h}$ for $6 \mathrm{~h}$, for determination of plasma FSH and prolactin concentrations. A further sample was collected to measure plasma TSH and thyroxine concentrations, while additional samples of blood that was either clotted, or used oxalate/fluoride anticoagulant $(7 \mathrm{ml}$ each), were collected to determine serum albumin, calcium and phosphorus and plasma glucose concentrations. The scrotal circumference of each ram was measured $1-7$ days after collection of blood samples, at which time semen was collected by electroejaculation. The rams were slaughtered at the end of the eighth month of the experiment (April).

\section{Experiment 1(b)}

A further 33 Welsh Mountain rams were thyroidectomized and $2 I$ animals underwent sham surgery in September. These animals were to be used for another experiment, but, in the period between September and the following February, were housed under conditions of natural photoperiod and were not subject to any experimental procedures other than collection of blood samples every two weeks and monthly measurements of scrotal circumference.

\section{Experiment 2}

This experiment complemented Expt 1 (a) and examined the effect of thyroidectomy upon rams that had previously been subjected to natural inhibitory photoperiod, and were at the nadir of their testicular growth cycle at the start of the experiment.

Thirty-four Welsh Mountain rams were maintained at pasture from February onwards. In early March, II animals were thyroidectomized, as in Expt $I(a)$, and 23 were untreated. Blood samples $(10 \mathrm{ml})$ were collected by jugular venepuncture before thyroidectomy and every two weeks thereafter until the end of the experiment (December), for determination of serum FSH, TSH and thyroxine concentrations. Scrotal circumference was measured every 4 weeks.

\section{Assay methods}

Plasma and serum FSH, TSH and prolactin concentrations were measured in duplicate $50 \mu \mathrm{l}$ samples, using established double-antibody procedures (McNeilly and Andrews, 1974;

Downloaded from Bioscientifica.com at 04/26/2023 11:19:06AM 
Fraser and McNeilly, 1982; McNeilly et al., 1986). Details of reagents and assay validation criteria are given in Table 1 .

Plasma and serum thyroxine concentrations were measured with a newly established radioimmunoassay. Sources of reagents are given in Table 1 . Duplicate $5 \mu$ l aliquots of plasma, diluted to a final volume of $40 \mu \mathrm{l}$ in barbital buffer ( $\mathrm{M}$ barbital, $\mathrm{pH} 7.4$ ), were incubated overnight at $4^{\circ} \mathrm{C}$ with a 1:7500 dilution of antiserum (see Table 1) and 7000 c.p.m. $\left[{ }^{125}\right.$ I]thyroxine. Standards $\left(0.1-50 \mathrm{ng} \mathrm{ml}^{-1}\right)$ were similarly dispensed in barbital buffer, to which $5 \mu$ l of stripped plasma was added per tube. Free and antibody-bound radioactivity were separated by the addition of $20 \mathrm{ml}$ of a 1:60 dilution of a second, anti-rabbit antibody, diluted in barbital buffer. After a second overnight incubation at $4^{\circ} \mathrm{C}$ and the addition of $200 \mathrm{ml}$ of barbital buffer plus $10 \mathrm{~g}$ egg albumin $1^{-1}$, tubes were centrifuged at $4^{\circ} \mathrm{C}$ for $60 \mathrm{~min}$ at $4500 \mathrm{~g}$. The supernatant was discarded and the radioactivity in the pellets counted for $2 \mathrm{~min}$. The assay was validated for use by demonstrating parallelism between a sample of plasma containing a high concentration of thyroxine, serially diluted in stripped plasma, and a series of standards made in stripped sheep plasma. Standards made in buffer alone were not parallel to those made in stripped plasma, hence the addition of stripped plasma to the standards tubes.

Concentrations of albumin, phosphate and calcium in serum, and of glucose in plasma, were determined by standard colorimetric methods (Human Gesellschaft fur Biochemica und Diagnostica mbH, Taunusstein; Reagents Applications Inc., San Diego, USA), using a Kone Specific Discrete Autoanalyser (Labmedics Ltd, Stockport). Interassay coefficients of variation over seven assays were $5.1,3.8,5.0$ and $4.0 \%$, respectively.

\section{Semen analysis}

Immediately after collection, the wave motion of each ejaculate was assessed by examining a drop of semen placed on a warm slide under $\times 100$ magnification. Ejaculates were classified from 0 (no motion) to 10 . Density was determined by counting semen diluted $1: 1000$ in buffered formol saline $10.9 \%$ $\mathrm{v}: \mathrm{w} \mathrm{NaCl}, 0.025 \%$ formalin) under $\times 400$ magnification in a haemacytometer. The morphology of the spermatozoa was assessed by mixing one drop of semen with 5-10 (depending upon density) drops of eosin/nigrosin and preparing smears on warmed microscope slides. One hundred spermatozoa were counted and classified according to Blom (1983). The number of morphologically normal, progressively motile spermatozoa was calculated as the product of ejaculate volume, concentration of spermatozoa and fractionate proportions of morphologically normal and motile spermatozoa.

\section{Statistical analysis}

All data were subjected to analysis of variance with respect to treatment and time (i.e. month) in a repeated-measures analysis, in which rams were nested within treatments. Where data were not normally distributed (plasma FSH and prolactin concentrations), they were subjected to logarithmic transformation before analysis of variance.

\section{Results}

\section{Experiment 1(a)}

Complete thyroidectomy was confirmed in all but two of the treated animals by high plasma TSH ( > $2.0 \mathrm{ng} \mathrm{ml}^{-1}$, compared with $<0.5 \mathrm{ng} \mathrm{ml}^{-1}$ in intact animals) and low plasma thyroxine concentrations $\left(<0.3 \mathrm{ng} \mathrm{ml}^{-1}\right.$, compared with $>4.0 \mathrm{ng} \mathrm{ml}^{-1}$ in intact animals) from the first blood sample and throughout the experiment (Fig. 1). The animals that were deemed to have been incompletely thyroidectomized initially showed high TSH and low thyroxine concentrations but, after several months, depression of TSH and an increase in thyroxine concentrations occurred. These animals, one per treatment group, were excluded from the investigation. Throughout the investigation, plasma glucose and serum albumin concentrations remained in the ranges $2.5-4.1 \mathrm{mmol} \mathrm{l}^{-1}$ and $27.6-$ $37.7 \mathrm{~g} \mathrm{l}^{-\mathrm{I}}$, respectively, and serum concentrations of calcium and phosphate remained above 2.1 and $0.7 \mathrm{mmol}^{-1}$, respectively. There were no significant effects of time or treatment upon any of these parameters.

There was a slight reduction in scrotal circumference in some groups of animals between October and December (both groups under $16 \mathrm{~h}$ light: $8 \mathrm{~h}$ dark, intact animals under $8 \mathrm{~h}$ light:16 h dark 8L:16D), but thereafter there were no significant decreases in the two groups of thyroidectomized rams (Fig. 2). By contrast, in the intact animals, whether kept under $8 \mathrm{~h}$ light: $16 \mathrm{~h}$ dark or $16 \mathrm{~h}$ dark: $8 \mathrm{~h}$ light, there was a progressive decline in scrotal circumference, and values were significantly lower than those in thyroidectomized rams in December, January and February (16 h light: $8 \mathrm{~h}$ dark: $P<0.05, P<0.01$, $P<0.01$, respectively; $8 \mathrm{~h}$ light: $16 \mathrm{~h}$ dark: $P<0.05, P<0.05$, $P<0.01$, respectively). Thus, in February, scrotal circumferences in intact animals on long days, short days and natural photoperiods were $23.5 \pm 0.3,22.6 \pm 1.4$ and $23.2 \pm 0.8 \mathrm{~cm}$, respectively, compared with $28.2 \pm 1.0$ and $26.8 \pm 1.8 \mathrm{~cm}$ in the thyroidectomized rams on long and short days, respectively. For the groups under long day photoperiod, this also applied in March, but some regrowth of the testes occurred in the control animals maintained under $8 \mathrm{~h}$ light: $16 \mathrm{~h}$ dark, such that the testes were no longer smaller than those of the thyroidectomized rams. By April, scrotal circumference had increased in both ( $8 \mathrm{~h}$ light:16 h dark and $16 \mathrm{~h}$ light: $8 \mathrm{~h}$ dark) groups of intact rams $(26.0 \pm 0.9$ and $25.6 \pm 1.5 \mathrm{~cm}$, respectively) and values were not significantly different from those of the thyroidectomized animals (short days: $26.8 \pm 1.0$; long days: $27.1 \pm 0.7 \mathrm{~cm}$ ). Scrotal circumference of the intact rams maintained in natural photoperiods exhibited an identical pattern of regression to that of the intact animals on either fixed photoperiod, except that values also remained low through April.

Between October and February, the thyroidectomized rams had significantly $(P<0.001)$ higher plasma FSH concentrations than those of any intact animals (Fig. 3). There were no significant differences between the groups of thyroidectomized animals maintained under long or short days, nor between animals kept in fixed or natural photoperiods. In March and April, FSH concentrations of intact animals maintained on long days began to increase, so that they became not significantly different from values in the thyroidectomized rams. However,
Downtoaded from Bioscientifica.com at $04 / 26 / 2023$ 11:19:06AM 

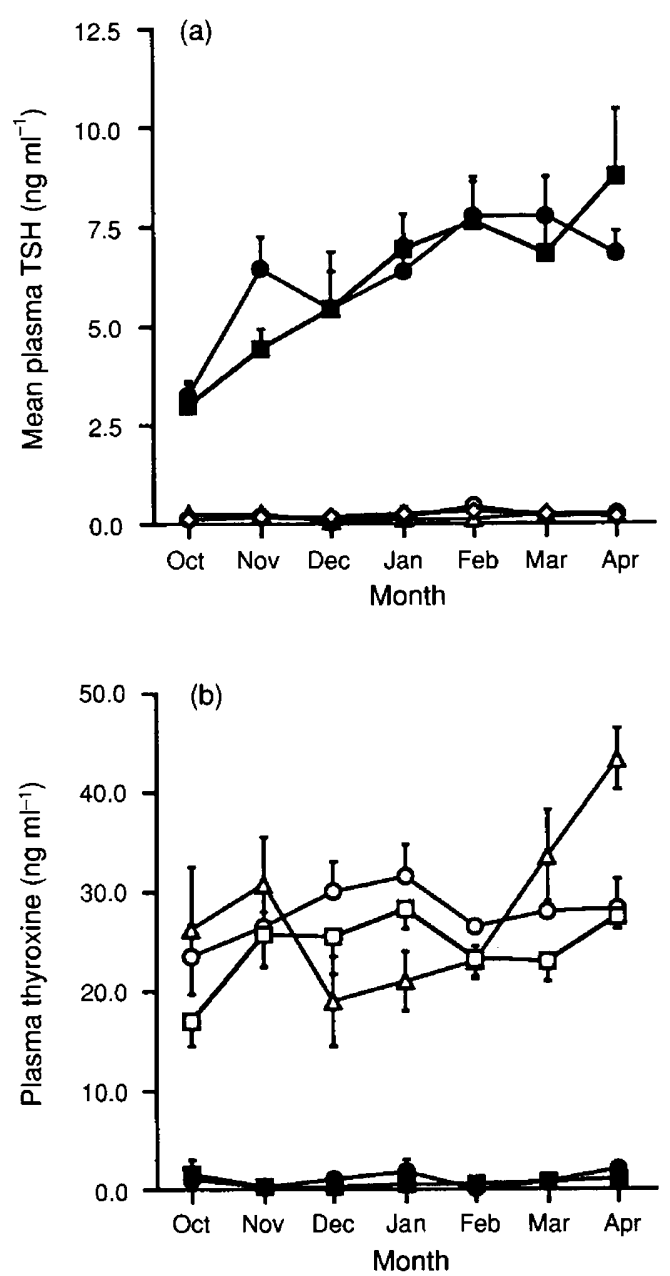

Fig. 1. Expt 1(a). Mean ( \pm SEM) plasma concentrations of (a) TSH and (b) thyroxine in rams after thyroidectomy or sham surgery. Values for thyroidectomized animals are significantly $(P<0.01)$ different from those of intact animals at all times. ( $\square$ ) Thyroidectomized, long days $(n=6) ;(\diamond)$ intact, long days $(n=6) ;(\bullet)$ thyroidectomized, short days $(n=6) ;(O)$ intact, short days $(n=6) ;(\triangle)$ intact, natural days $(n=6)$.

concentrations in intact rams maintained at $8 \mathrm{~h}$ light: $16 \mathrm{~h}$ dark or natural photoperiods remained significantly $(P<0.01)$ lower than those in the thyroidectomized rams maintained at short days.

Plasma concentrations of prolactin exhibited a similar pattern in the groups of thyroidectomized and intact rams maintained under $8 \mathrm{~h}$ light: $16 \mathrm{~h}$ dark, which were also similar to values in thyroidectomized rams maintained at $16 \mathrm{~h}$ light: $8 \mathrm{~h}$ dark. However, after November, values in the intact rams on long days ( $16 \mathrm{~h}$ light: $8 \mathrm{~h}$ dark) were significantly higher than those in all other groups of animals on fixed photoperiods. In the intact animals in natural photoperiods, concentrations of prolactin declined to a nadir in November and then progressively increased throughout the remainder of the experiment. By April, mean prolactin concentration was significantly higher in this group than in any of the groups held on fixed photoperiod.

Both thyroidectomized and intact animals produced motile, morphologically normal spermatozoa throughout the
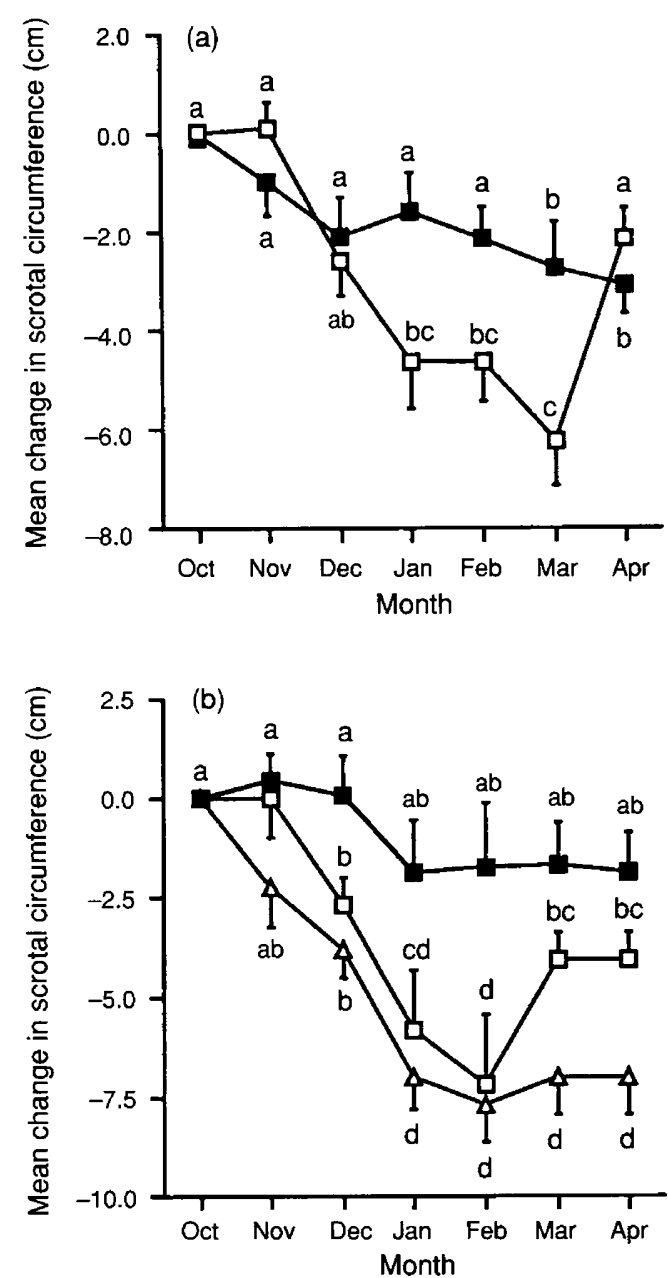

Fig. 2. Expt 1(a). Mean ( \pm SEM) change in scrotal circumference of thyroidectomized and intact rams maintained in (a) long days (16 h light: $8 \mathrm{~h}$ dark) or (b) short days ( $8 \mathrm{~h}$ light:16 h dark) and natural photoperiods. ( $)$ Thyroidectomized rams $(n=6)$; $(\square)$ intact rams $(n=6) ;(\triangle)$ intact rams, natural photoperiod $(n=6)$. Points not labelled with a common letter are significantly different from each other $(P<0.05)$.

experiment. The mean number of spermatozoa per ejaculate that were both motile and morphologically normal is shown (Fig. 5). In November, numbers of spermatozoa were not significantly different in intact and thyroidectomized rams, but in January, numbers in intact rams were significantly $(P<0.05)$ lower than those in November and lower than in thyroidectomized rams during January $(P<0.05)$ and also lower than in intact animals during November $(P<0.05)$. There were no differences in the percentage of progressively motile spermatozoa, nor in the percentages of spermatozoa exhibiting either major or minor morphological abnormalities.

\section{Experiment 1(b)}

Before surgery (September), the mean scrotal circumference of rams that were to be thyroidectomized was $31.0 \pm 0.4 \mathrm{~cm}$, compared with $31.4 \pm 0.5 \mathrm{~cm}$ in rams that were to undergo 

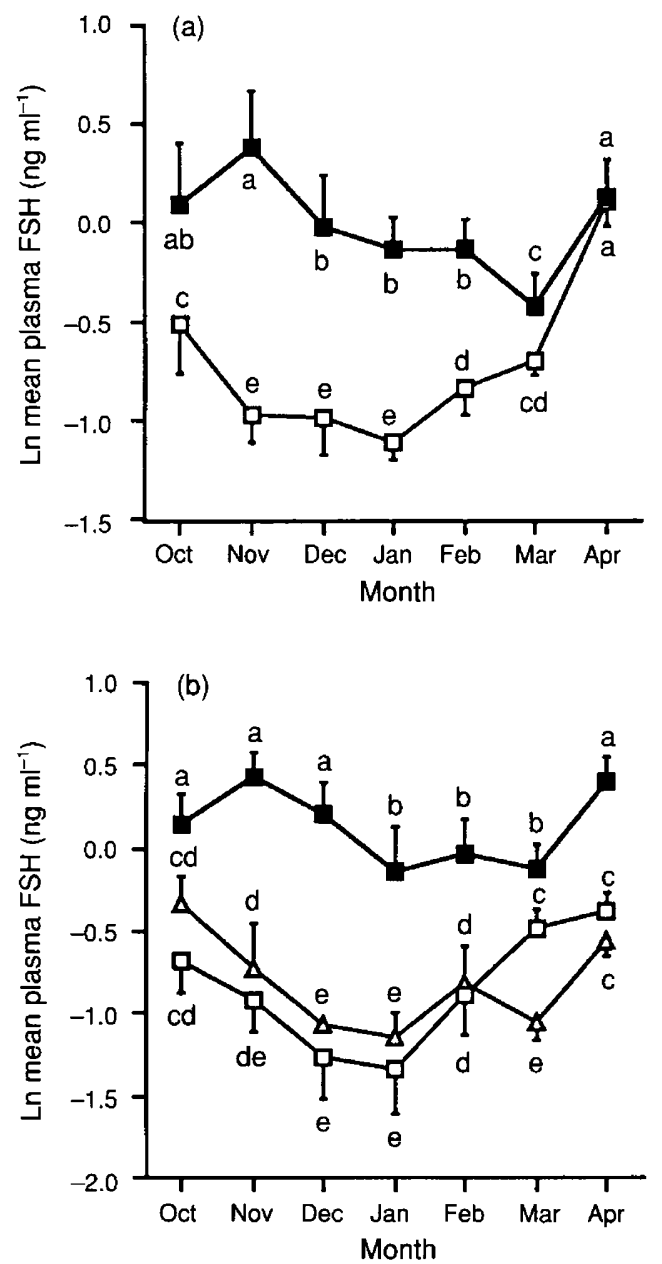

Fig. 3. Expt 1. Mean ( \pm SEM) $\log _{e}$ plasma FSH concentrations of thyroidectomized and intact rams maintained in (a) long days (16 h light: $8 \mathrm{~h}$ dark) or (b) short days ( $8 \mathrm{~h}$ light:16 $\mathrm{h}$ dark) and natural photoperiods. ( $\square)$ Thyroidectomized rams $(n=6) ;(\square)$ intact rams $(n=6) ;(\triangle)$ intact rams, natural photoperiod $(n=6)$. Points not labelled with a common letter are significantly different from each other $(P<0.05)$.

sham surgery. By February, the mean value in thyroidectomized rams had declined slightly $(28.1 \pm 0.4 \mathrm{~cm} ; P<0.05)$, but remained greater than that in the sham-operated controls $(23.8 \pm 0.5 \mathrm{~cm})(P<0.001)$.

\section{Experiment 2}

Successful thyroidectomy was confirmed in all 11 rams by demonstrating high plasma TSH and low thyroxine concentrations in all blood samples collected after thyroidectomy (data not shown).

At the outset of the experiment (March), the testes of all rams were at minimal size (scrotal circumference: $24.6 \pm 0.6 \mathrm{~cm}$; $n=34$ ). The mean scrotal circumference of the thyroidectomized rams increased significantly $(P<0.01)$ in the 8 weeks after thyroidectomy (Fig. 6) to $31.0 \pm 0.6 \mathrm{~cm}$, a value similar to that of the rams at the start of Expt 1. In the intact animals, a very much slower rate of increase in scrotal size occurred, such
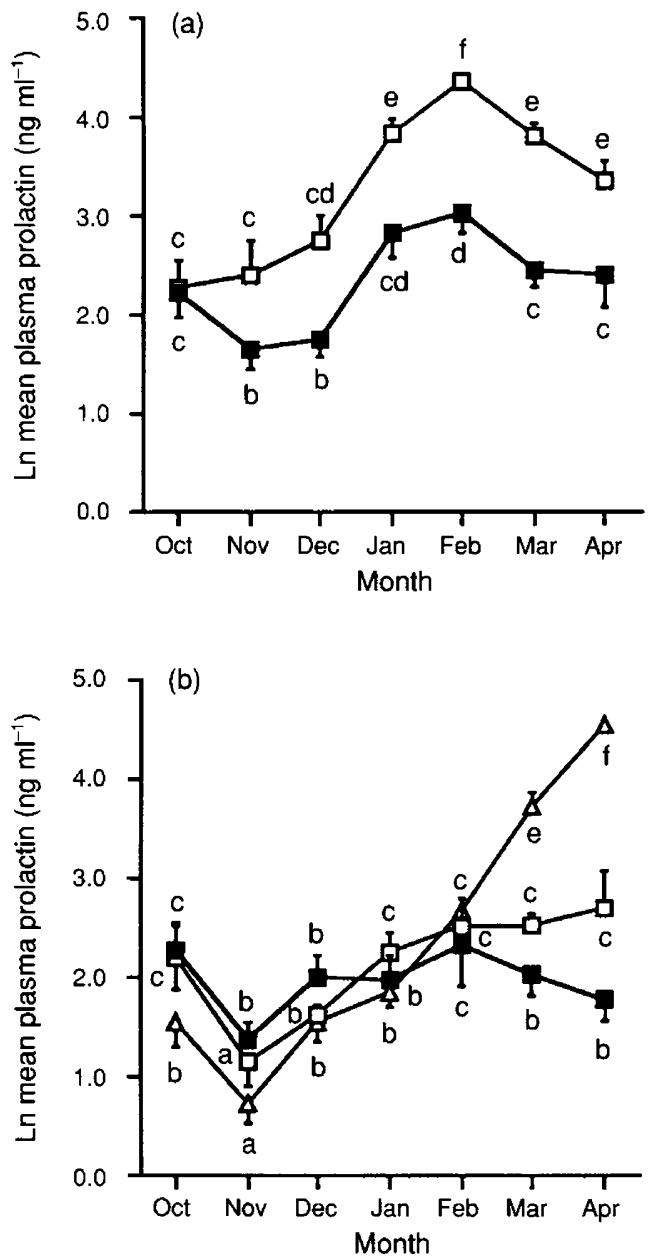

Fig. 4. Mean ( \pm SEM) $\log _{e}$ plasma prolactin concentrations of thyroidectomized and intact rams maintained in (a) long days ( $16 \mathrm{~h}$ light: $8 \mathrm{~h}$ dark) or (b) short days ( $8 \mathrm{~h}$ light:16 h dark) and natural photoperiods. ( $\square$ ) Thyroidectomized rams $(n=6)$; $(\square)$ intact rams $(n=6) ;(\triangle)$ intact rams, natural photoperiod $(n=6)$. Points not labelled with a common letter are significantly different from each other $(P<0.05)$.

that values in the thyroidectomized animals were significantly greater than those in intact rams between April and August. Eventually, scrotal size in the intact rams became similar in both groups of animals and remained so until the termination of the experiment in December.

Mean plasma concentrations of FSH (Fig. 7) were significantly higher in the first sample collected after surgery from the thyroidectomized rams than either pre-operative concentrations $(P<0.01)$ or values in intact animals $(P<0.01)$. Mean FSH concentrations remained significantly $(P<0.01)$ higher in thyroidectomized rams from April-June. By August, however, a significant $(P<0.01)$ decline in plasma FSH concentrations had occurred in the thyroidectomized rams, whereas FSH concentrations in the intact animals had progressively increased since June. Thus, FSH concentrations became similar in both groups in July and were significantly $(P<0.05)$ higher in intact than in thyroidectomized animals during August and September. In October, concentrations of plasma FSH began to decline sharply in the intact animals, but were maintained in the
Downloaded from Bioscientifica. com at $04 / 26 / 2023$ 11:19:06AM 


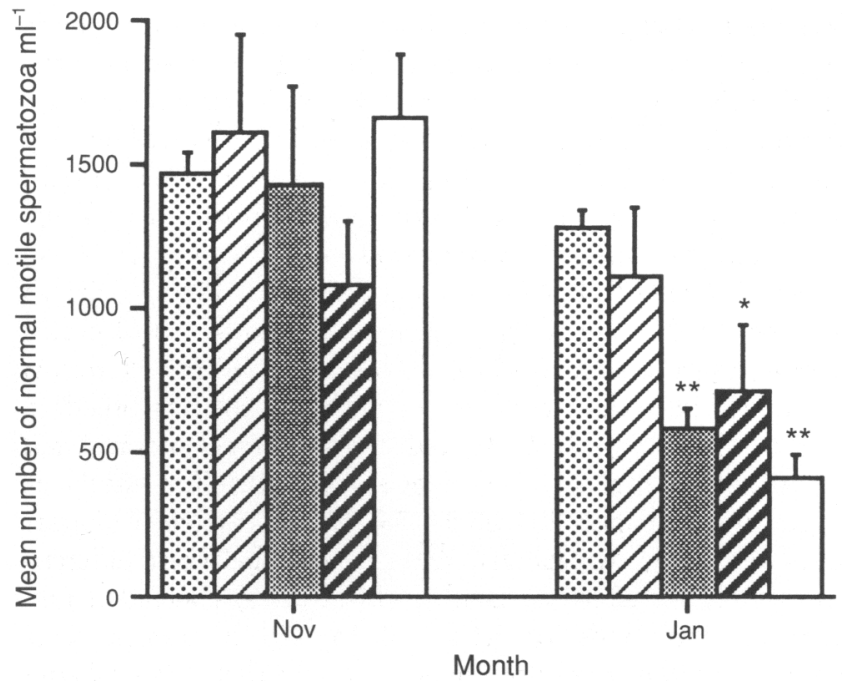

Fig. 5. Mean ( \pm SEM) number of morphologically normal, progressively motile spermatozoa collected by electroejaculation in November and January from thyroidectomized and intact rams. The mean values were significantly lower in January than in November as indicated $(* P<0.05 ; * * P<0.01)$. (国) Thyroidectomized, long days $(n=6)$; (Z) thyroidectomized, short days $(n=6)$; (畻) intact, long days $(n=6)$; $(\square)$ intact, short days $(n=6) ;(\square)$ intact, natural days $(n=6)$.

thyroidectomized rams, so that, by December, FSH concentrations in thyroidectomized rams were again significantly $(P<0.05)$ greater than those in intact animals.

\section{Discussion}

The findings of the experiments reported here support the hypothesis that the thyroid gland exerts a crucial role in transitions between the breeding and non-breeding season of rams. Other studies have indicated a role for the thyroid in such transitions in ewes (Nicholls et al., 1988b; Follett and Potts, 1990; Moenter et al., 1991; Webster et al., 1991a, b); these results are confirmed and extended to rams by the present observations. It is therefore probable that, as postulated by Nicholls $e$ al. (1988b), the activity of the thyroid gland is required for normal expression of circannual cycles of reproductive activity across a wide phylogenetic spectrum and may, indeed, act as a final common pathway in permitting the generation of such cycles.

The work of Karsch's group (Moenter et al., 1991; Webster et al, 1991a, b) has indicated that thyroidectomy of ewes at the time of the transition from the non-breeding to breeding seasons extends the breeding season, by preventing the return to anoestrus during increasing photoperiod after the winter solstice. The study reported here confirms that a similar extension of the breeding season also occurs in rams. However, the detailed design of these experiments differed in that the rams in Expts I(a) and (b) were all thyroidectomized well after the onset of the male's breeding season, when testicular size was already at its seasonal maximum. By comparison, many of the long-term studies of the responses of ewes and red deer stags to thyroidectomy (for example Shi and Barrell, 1992)

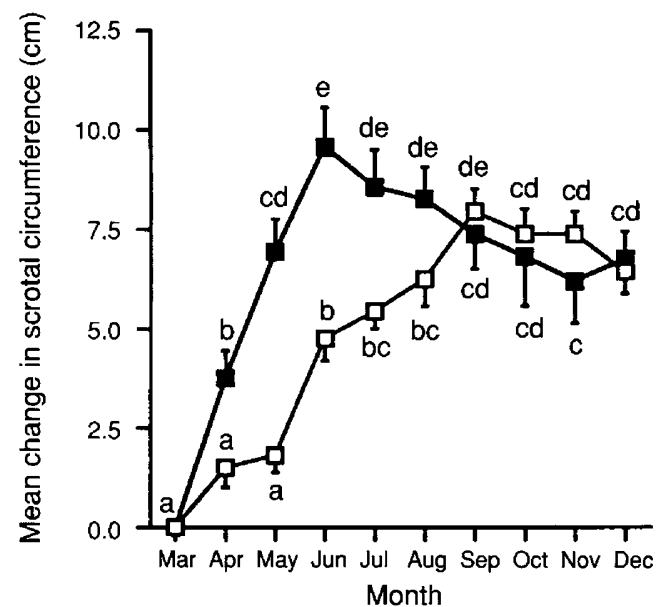

Fig. 6. Expt 2. Mean ( \pm SEM) change in scrotal circumference of thyroidectomized ( $\square, n=11$ ) and intact $(\square, n=23$ ) rams maintained in natural photoperiods. Points not labelled with a common letter are significantly different from each other $(P<0.05)$.

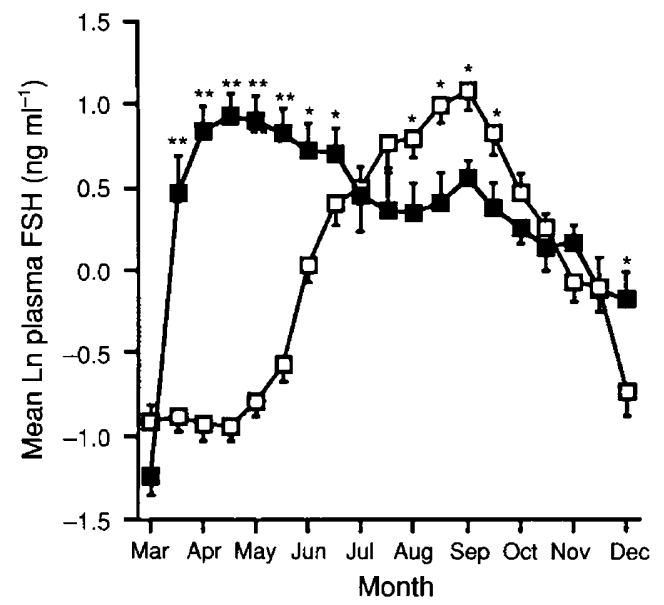

Fig. 7. Expt 2. Mean ( \pm SEM) $\log _{e}$ plasma FSH concentrations in thyroidectomized ( $\square, n=11$ ) and intact ( $\square, n=23$ ) Welsh Mountain rams maintained in natural photoperiods. Differences between means are statistically significant where indicated $\left({ }^{*} P<0.05,{ }^{* *} P<0.01\right)$.

used animals that were thyroidectomized at about the time of the transition between the non-breeding and breeding seasons, or early in the breeding season. The significance of this difference in timing of thyroidectomy has to be understood in relation to the results of Malpaux et al. (1988), who demonstrated that the transition from the breeding to non-breeding season of ewes is endogenously regulated and not amenable to manipulation by photoperiod-based regimens. Thus, following the hypothesis of these authors, once the breeding season has started, its termination is an expression of the endogenous rhythm of activity, rather than a response to changes in daylength. The present study indicates that, even when rams are thyroidectomized at a time when endogenous termination of the reproductive cycle would be expected to be inevitable, the breeding season is extended.

Downloaded from Bioscientifica.com at 04/26/2023 11:19:06AM 
Further evidence to support the contention of Malpaux et al. (1988) is derived from the similarity of responses of the rams maintained under the very different photoperiodic regimens in Expt Ia. Although groups of intact rams were maintained under both stimulatory and inhibitory daylengths, the rate of decline of testicular size was similar in both groups. Thus, all these intact rams were subject to an endogenously mediated onset of reproductive quiescence, which was not affected by photoperiod. Since neither thyroidectomized group underwent major testicular regression, it seems that thyroidectomy extends the breeding season of rams, even when the animals are about to enter a period of endogenously mediated photorefractoriness. Webster et al. (1991a), who thyroidectomized ewes at a time after the onset of their breeding season when photorefractoriness would also be considered to be inevitable, similarly concluded that the maintenance of the reproductive activity of the ewes indicated an abrogation of endogenous photorefractoriness.

The effects of thyroidectomy at the nadir of the circannual cycle of reproductive activity has not previously been studied in domestic mammals. The results of Expt 2 indicate that a rapid stimulation of reproductive activity occurs after thyroidectomy, such that plasma FSH concentrations of thyroidectomized rams were significantly higher than control values 2 weeks after thyroidectomy, and scrotal circumference had increased 2 weeks later. This rapid regrowth of the testis underlines the importance of the thyroid for the existence and maintenance of the non-breeding season. It also hints at the possible underlying inhibitory neural mechanisms being rapidly removed in the absence of thyroxine. It is, however, possible that some residual seasonality remains in these animals, for all groups of thyroidectomized rams did exhibit some decline in scrotal circumference and FSH concentrations some time after surgery, as did the stags in the study of Shi and Barrell (1992). If these changes do indicate residual seasonality, the inferences would be, first, that the thyroid is merely required for complete testicular regression and therefore does not exert a critical role in the generation of circannual cycles and, second, that males differ in their response to thyroidectomy from females, in which seasonality is fully abrogated (Webster et al., 1991a). Comparison with the situation in birds and an examination of the wider effects of thyroidectomy upon neuroendocrine activity is valuable for evaluating these possibilities.

When starlings are thyroidectomized before the breeding season commences, testicular growth occurs in long days and the testes remain large indefinitely (Wieselthier and van Tienhoven, 1972; Goldsmith and Nicholls, 1984; Nicholls et al., $1988 \mathrm{a}, \mathrm{b}$ ), in a very similar manner to that observed in sheep. If starlings are thyroidectomized in the non-breeding season when they are photoperiodically refractory, that refractory state is dissipated spontaneously, as it is in sheep. There is an apparent difference, however, because testicular growth in starlings depends more upon photoperiod change than it does in sheep. Thus, thyroidectomy of starlings on long days leads to spontaneous testicular development, whereas development in birds on short days is very slow.

Surprisingly, the results of Expt 1 (a) infer that the effect of thyroidectomy upon gonadotrophin secretion is somewhat different from that upon prolactin or melatonin. In Expt 1, the prolactin concentrations of intact animals maintained on long days were, as expected, higher than those of animals on short days. By contrast, both groups of thyroidectomized animals, whether on long or short days, had similar, low concentrations of prolactin. A similar result was reported for starlings by Goldsmith and Nicholls (1984) and Dawson et al. (1985), although this has not previously been shown for sheep. Melatonin, by contrast, continues to exhibit patterns of secretion that reflect photoperiod (Nicholls et al., 1988a). FSH, as described above, exhibits a different response to thyroidectomy; Webster et al. (1991b) showed that GnRH secretion is maintained in thyroidectomized ewes during the non-breeding season, suggesting that thyroid hormones act upon brain centres higher than the GnRH pulse oscillator. The effects of thyroidectomy upon the endocrine system therefore appear to be relatively widespread and to vary between different neuroendocrine effectors. Dahl et al. (in press) concluded that whatever the mode of action of thyroid hormones, it is permissive rather than dose dependent and that it is probably mediated through higher neuronal links to the GnRH neurones, rather than to the GnRH neurone itself. Furthermore, the results of Expt 1(a) provide evidence that the response to thyroidectomy is not due to widespread perturbation of the metabolic homeostasis of the rams, for parameters of energy and protein balance (glucose and albumin concentrations) indicated that these were unaffected by thyroidectomy. The results of all of these studies therefore suggest that thyroidectomy primarily results in a disinhibition of reproductive activity, an observation which is likely to be of value in understanding the means by which reproductive activity is inhibited in the non-breeding season.

The authors thank A. E. Waterman for anaesthetising rams for surgery and A. S. McNeilly for gifts of antisera. Ovine prolactin was kindly iodinated by A. Goldsmith. The invaluable technical support of J. Douthwaite, J. Ford, B. Rosevink and S. Leader is also gratefully acknowledged. This study was funded by AFRC grants to T. J. Parkinson, B. K. Follett and the Photoperiodism and Reproduction Group.

\section{References}

Barrell GK and Lapwood KR (1979) Effects of modifying olfactory and pineal gland function on the seasonality of semen production and plasma hormone levels in rams Animal Reproduction Science 1 213-218

Blom E (1983) Pathological conditions in the genital organs and in the semen as grounds for rejection of breeding bulls for import or export to or from Denmark, 1958-1982 Nordisk Veterinaermedicin 35 105-130

Brookes JR, Ross CF and Turner CW (1965) Effect of thyroidectomy on reproductive performance of ewes and semen quality of rams Journal of Animal Science 25 55-58

Chandrasekhar Y, Holland MK, D'Occhio MJ and Setchell BP (1985) Spermatogenesis, seminal characteristics and reproductive hormone levels in mature rams with induced hypothyroidism and hyperthyroidism Journal of Endocrinology 105 39-46

Dahl GE, Evans NP, Moenter SM and Karsch FJ The thyroid gland is required for reproductive neuroendocrine responses to photoperiod in the ewe Endocrinology (in press)

Dawson A, Follett BK, Goldsmith AR and Nicholls TJ (1985) Hypothalamic gonadotrophin-releasing hormone and pituitary and plasma FSH and prolactin during photostimulation and photorefractoriness in intact and thyroidectomized starlings Joumal of Endocrinology 105 71-73

English J, Poulton AL, Arendt J and Symons AM (1986) A comparison of the efficiency of melatonin treatments in advancing oestrus in ewes Journal of Reproduction and Fertility 77 321-327

Downloaded from Bioscientifica.com at 04/26/2023 11:19:06AM 
Follett BK and Nicholls TJ (1985) Influences of thyroidectomy and thyroxine replacement on photoperiodically-controlled reproduction in quail Journal of Endocrinology 107 211-221

Follett BK and Potts C (1990) Hypothyroidism affects reproductive refractoriness and the seasonal oestrous period in Welsh Mountain ewes Journal of Endocrinology 127 103-109

Fraser HM and McNeilly AS (1982) Effect of chronic immunoneutralization of thyrotropin-releasing hormone on the hypothalamic-pituitary-thyroid axis, prolactin, and reproductive function in the ewe Endocrinology 111 19641973

Goldsmith AR and Nicholls TJ (1984) Thyroidectomy prevents the development of photorefractoriness and the associated rise in plasma prolactin in starlings General and Comparative Endocrinology 54 256-263

Goldsmith AR, Nicholls TJ and Plowman G (1985) Thyroxine treatment facilitates prolactin secretion and induces a state of photorefractoriness in thyroidectomized starlings Journal of Endocrinology 104 99-103

Jaquet J-M, Coutant C, Maurel B, Boissin-Agasse L and Boisson J (1986) Influence de la thyroidectomie sur les variations, au cours du printemps et de l'été de l'activitie testiculaire et de la prolactinemie chez le vison Comptes Rendus de l'Academie des Sciences [III] (Paris) 303 367-370

Karsch FJ, Bitmann EL, Foster DL, Goodman RL, Legan SJ and Robinson JE (1984) Neuroendocrine basis of seasonal reproduction Recent Progress in Hormone Research 40 185-225

Legan SJ and Karsch FJ (1980) Photoperiodic inhibition of seasonal breeding in ewes: modulation of the negative feedback action of estradiol Biology of Reproduction 23 1061-1068

Lincoln GA and Ebling FJP (1985) Effect of constant-release implant of melatonin on seasonal cycles in reproduction, prolactin secretion and moulting in rams Journal of Reproduction and Fertility 73 241-253

Lincoln GA and Short RV (1980) Seasonal breeding: nature's contraceptive Recent Progress in Hormone Research 36 1-43

McNeilly AS and Andrews P (1974) Purification and characterisation of caprine prolactin Joumal of Endocrinology 60 359-367

McNeilly AS, Jonassen JA and Fraser HM (1986) Suppression of follicular development after chronic LHRH immunoneutralization in the ewe Journal of Reproduction and Fertility 76 481-490

Malpaux B, Wayne NL and Karsch FJ (1988) Termination of the breeding season in the Suffolk ewe: involvement of an endogenous rhythm of reproduction Biology of Reproduction 39 254-263
Moenter SM, Woodfill CII and Karsch FJ (1991) Role of the thyroid gland in seasonal reproduction: thyroidectomy blocks seasonal suppression of reproductive neuroendocrine activity in ewes Endocrinology 128 1337-1344

Nicholls TJ, Follett BK, Goldsmith AR and Pearson H (1988a) Possible homologies between photorefractoriness in sheep and birds: the effect of thyroidectomy on the length of the ewe's breeding season Reproduction, Nutrition and Development 28 375-385

Nicholls TJ, Goldsmith AR and Dawson A (1988b) Photorefractoriness in birds and comparison with mammals Physiological Reviews 68 133-176

O'Callaghan D, Karsch FJ, Boland MP and Roche JF (1991) Role of short days in timing the onset and duration of reproductive activity in ewes under artificial photoperiods Biology of Reproduction 44 23-28

Poulton AL and Robinson TJ (1987) The response of rams and ewes of three breeds to artificial photoperiod Journal of Reproduction and Fertility $\mathbf{7 9}$ $609-626$

Poulton AL, Symons AM, Kelly IM and Arendt J (1987) Intraruminal soluble glass boluses containing melatonin can induce early onset of ovarian activity in ewes Joumal of Reproduction and Fertility 80 235-239

Robinson JJ, Wallace JM, Aitken RP and Wigzell S (1992) Effect of duration of melatonin treatment on the onset and duration of oestrous cyclicity in ewes Joumal of Reproduction and Fertility 95 709-717

Shi ZD and Barrell GK (1992) Requirement of thyroid function for the expression of seasonal reproductive and related changes in red deer (Cervus elaphus) stags Journal of Reproduction and Fertility 94 251-259

Ward SJ and Williams HLl (1987) Out-of-season breeding in adult Suffolk ewes following light and melatonin treatment Animal Production 44 485-498

Webster JR, Moenter SM, Woodfill CJI and Karsch FJ (1991a) Role of the thyroid gland in seasonal reproduction. II. Thyroxine allows a season-specific suppression of gonadotropin secretion in sheep Endocrinology 129 176-183

Webster JR, Moenter SM, Barrell GK, Lehman MN and Karsch FJ (1991b) Role of the thyroid gland in seasonal reproduction. III. Thyroidectomy blocks seasonal suppression of gonadotropin-releasing hormone secretion in sheep Endocrinology 129 1635-1643

Wieselthier AS and van Tienhoven A (1972) The effect of thyroidectomy on testicular size and on the photorefractory period in the starling (Sturnus vulgaris) Journal of Experimental Zoology 179 331-338

Yeates NTM (1949) The breeding season of the sheep with particular reference to its modification by artificial means using light Journal of Agricultural Science 39 1-43 